\title{
Small Molecule Inhibition of Protein Disulfide Isomerase in Neuroblastoma Cells induces Oxidative Stress Response and Apoptosis Pathways
}

\section{Dennis Özcelikf $\|^{*}$, John Paul Pezacki†ł}

† Department of Chemistry and Biomolecular Sciences, University of Ottawa, 10 Marie Curie Street, Ottawa, ON, Canada, K1N 6N5

|| Present address: Department of Drug Design and Pharmacology, University of Copenhagen, Universitetsparken 2, 2100 Copenhagen, Denmark

‡ Department of Biochemistry, Microbiology, and Immunology, Ottawa Institute for Systems Biology, 451 Smyth Road, Ottawa, ON, Canada, K1H 8M5

*Email: dennis.ozcelik@sund.ku.dk

\section{Keywords}

ER stress, oxidative stress, p53, microarray, neuropharmacology, click chemistry 


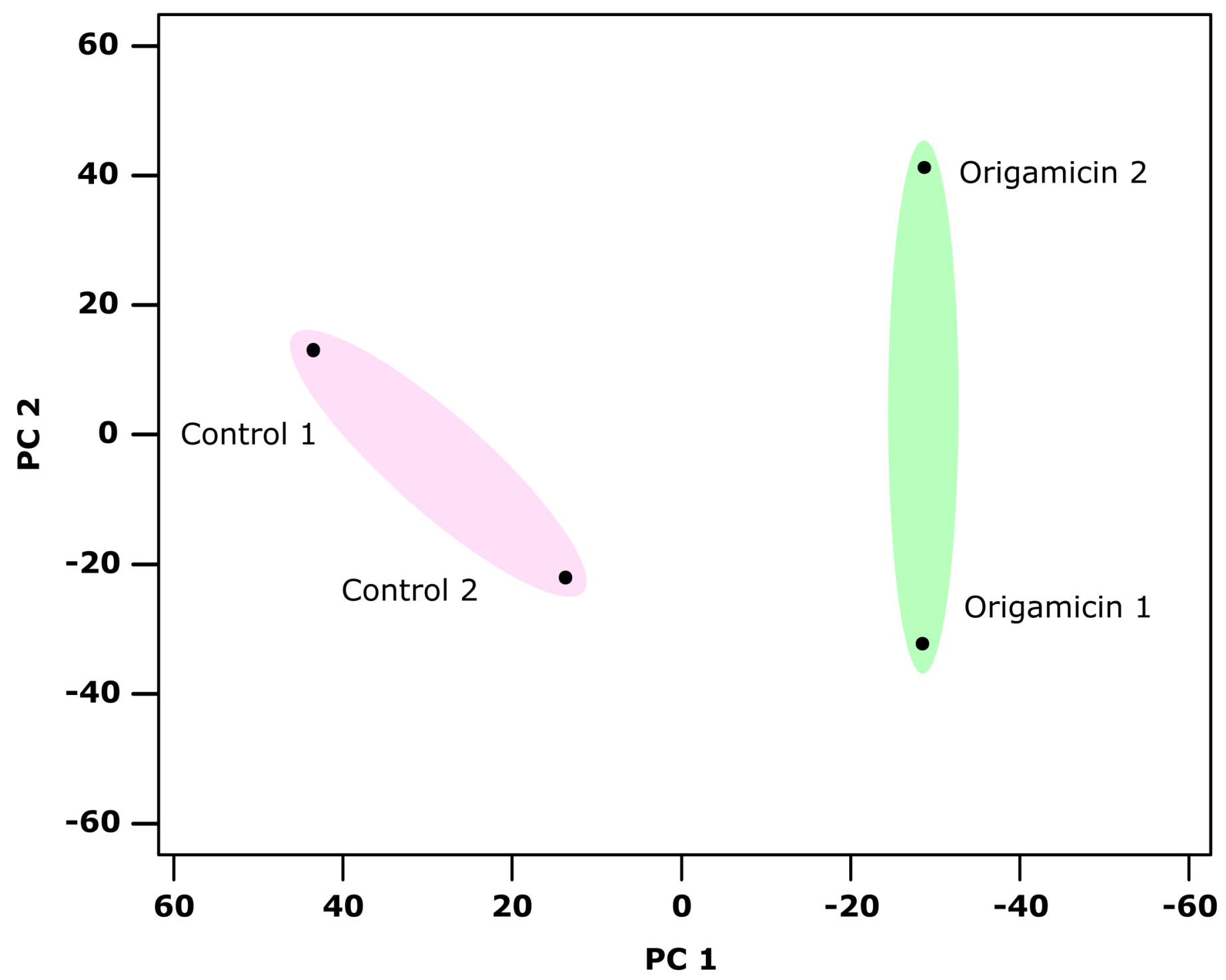

Figure S1. Principal component analysis (PCA) shows similarities in microarray gene expression profiles. Each black circle in the similarity matrix represents an individual microarray. 


\section{Expression change}
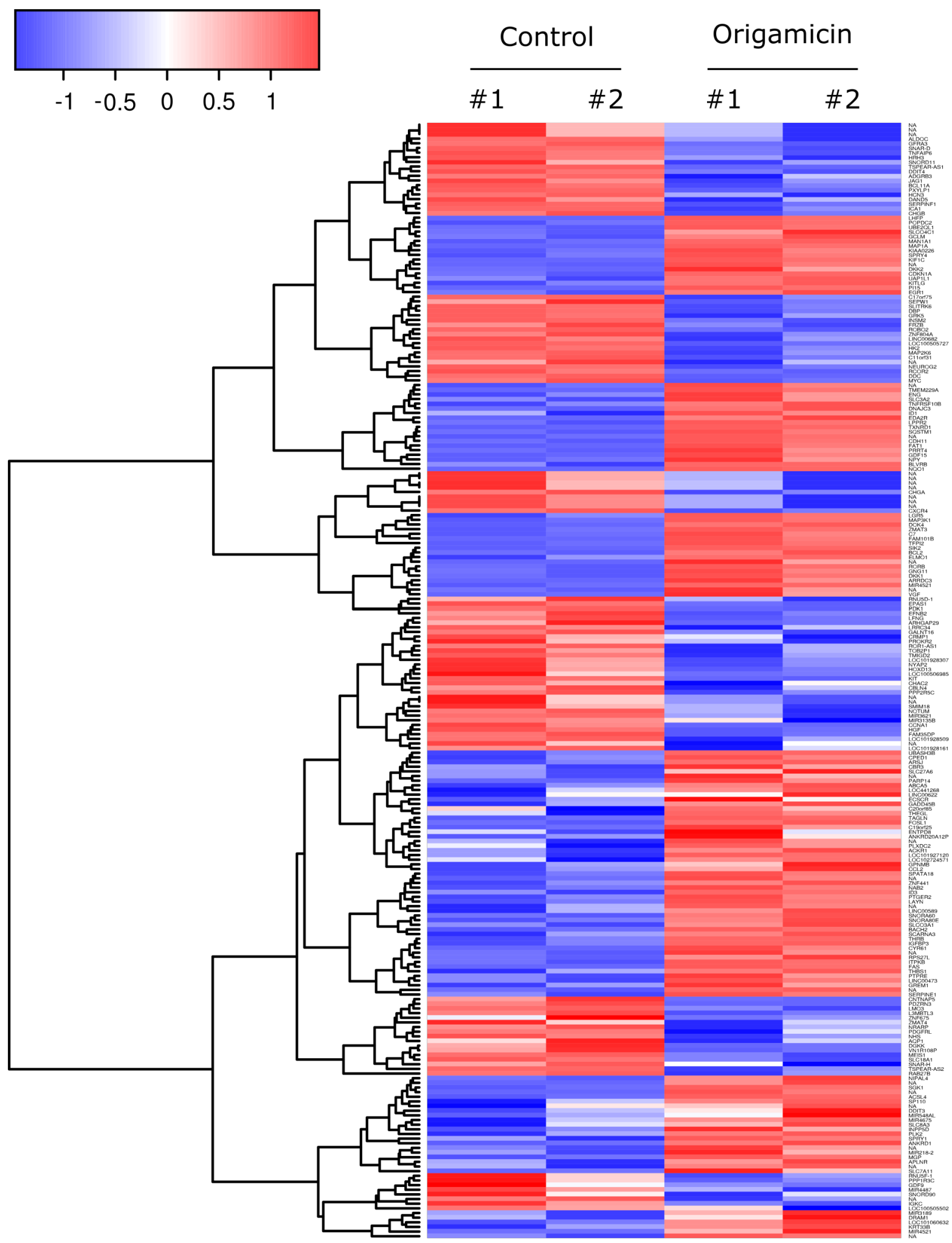

Figure S2. Heatmap and hierarchical clustering of 207 differentially expressed genes (cut-off $>1.5-$ fold change) identified in all four microarray data sets. 


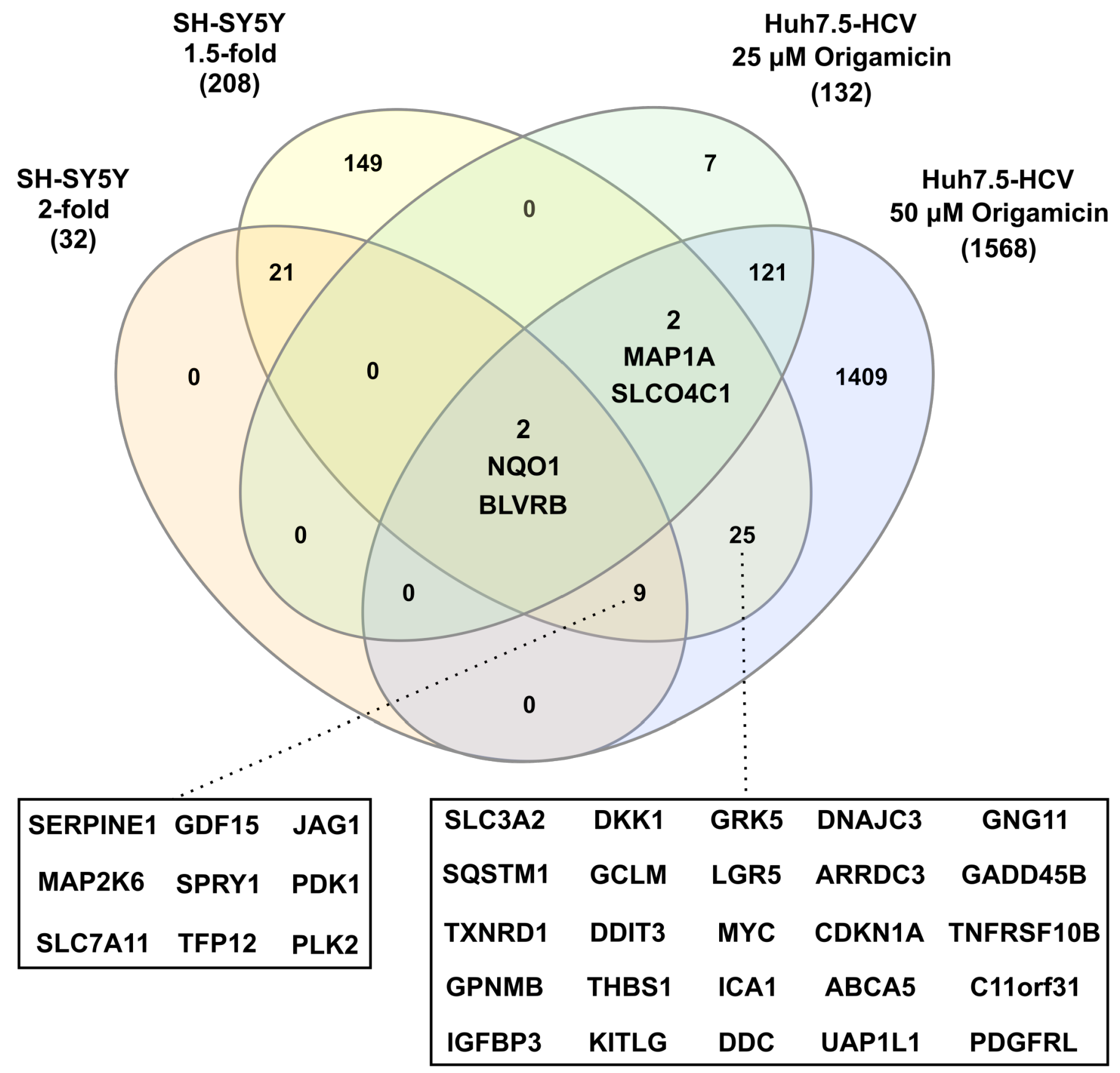

Figure S3. Venn diagram illustrates overlaps of identified DEGs in this and a previous study using SH-SY5Y (cut-off > 1.5-fold change or > 2-fold) or Huh7.5 cells harboring a HCV subgenomic replicon (treatment with $25 \mu \mathrm{M}$ or $50 \mu \mathrm{M}$ origamicin), respectively. Sum of all genes in the individual sample is presented in brackets. Genes shared among several samples are presented. 


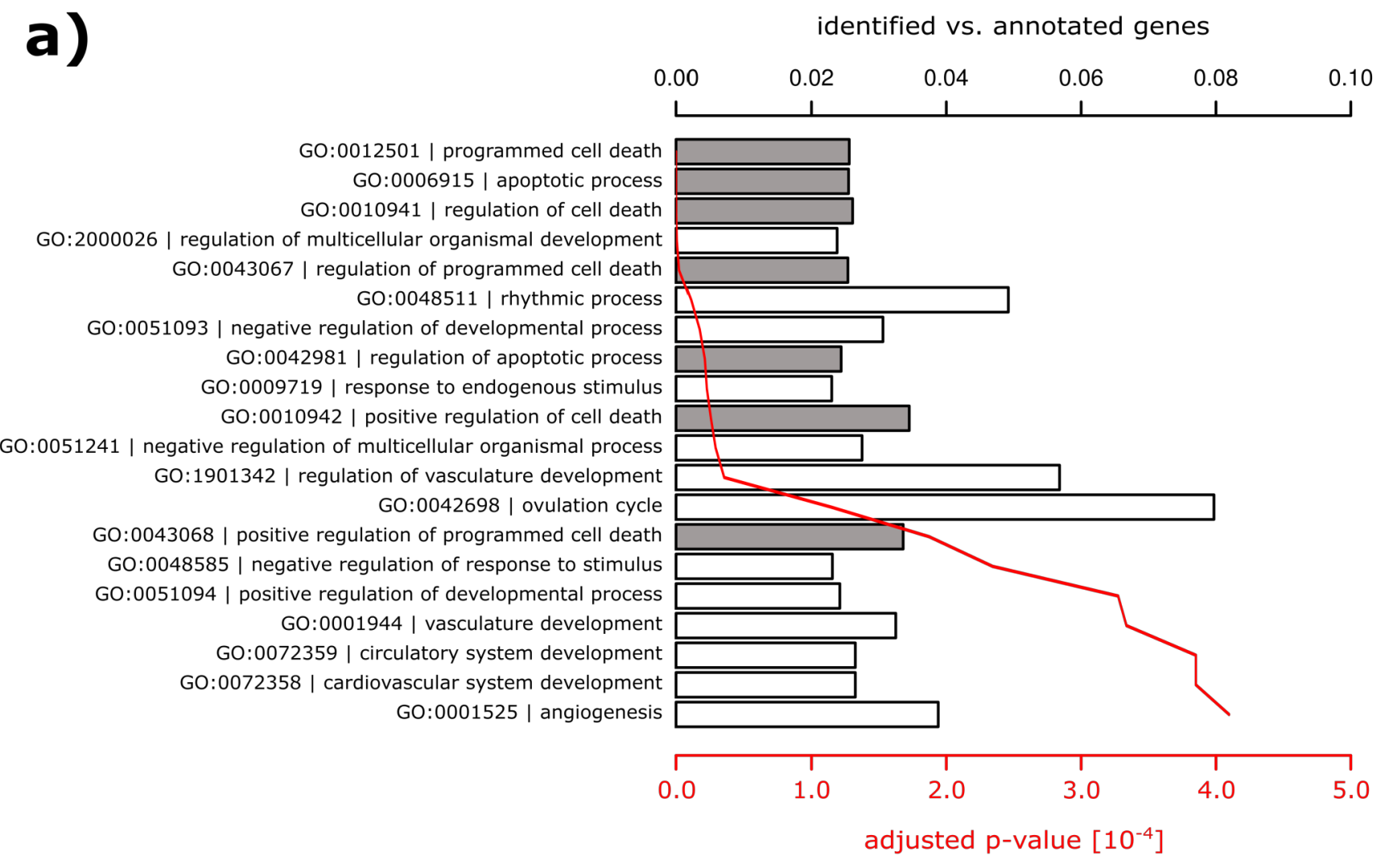

b) identified vs. annotated genes

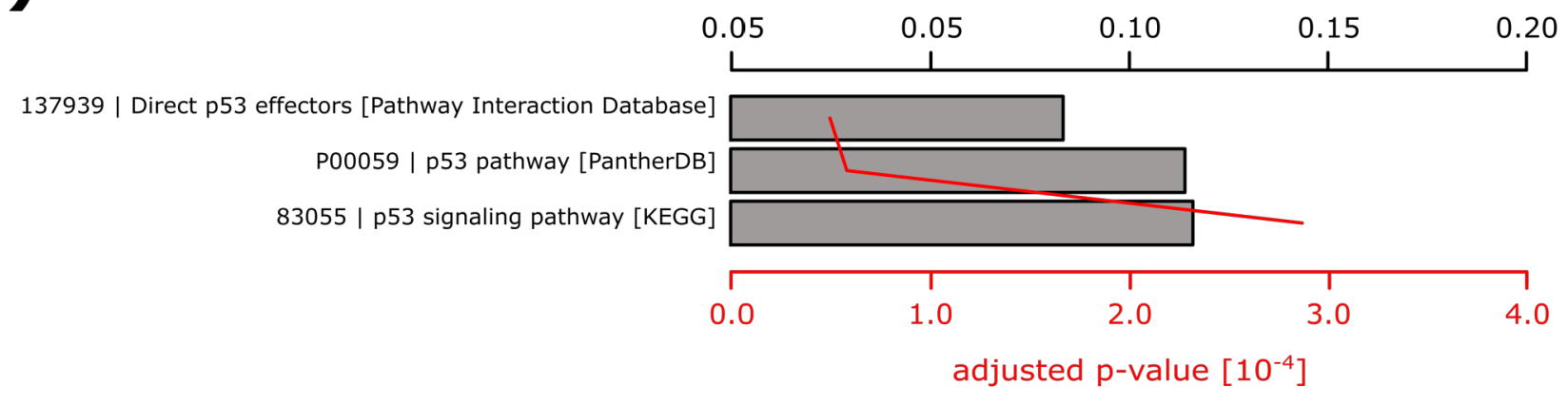

Figure S4. Gene ontology and pathway analysis. DEGs with at least 1.5 -fold expression change were (a) classified according to biological processes or (b) analyzed for pathway enrichment using ToppGene. Bars represent the ratio of identified genes versus all annotated genes in the corresponding biological classification or pathway, respectively. Only top 20 biological processes are presented. Multiple testing correction was performed according to the method of Bonferroni and produced an adjusted $p$-value depicted as red curve. 
a)

identified vs. annotated genes

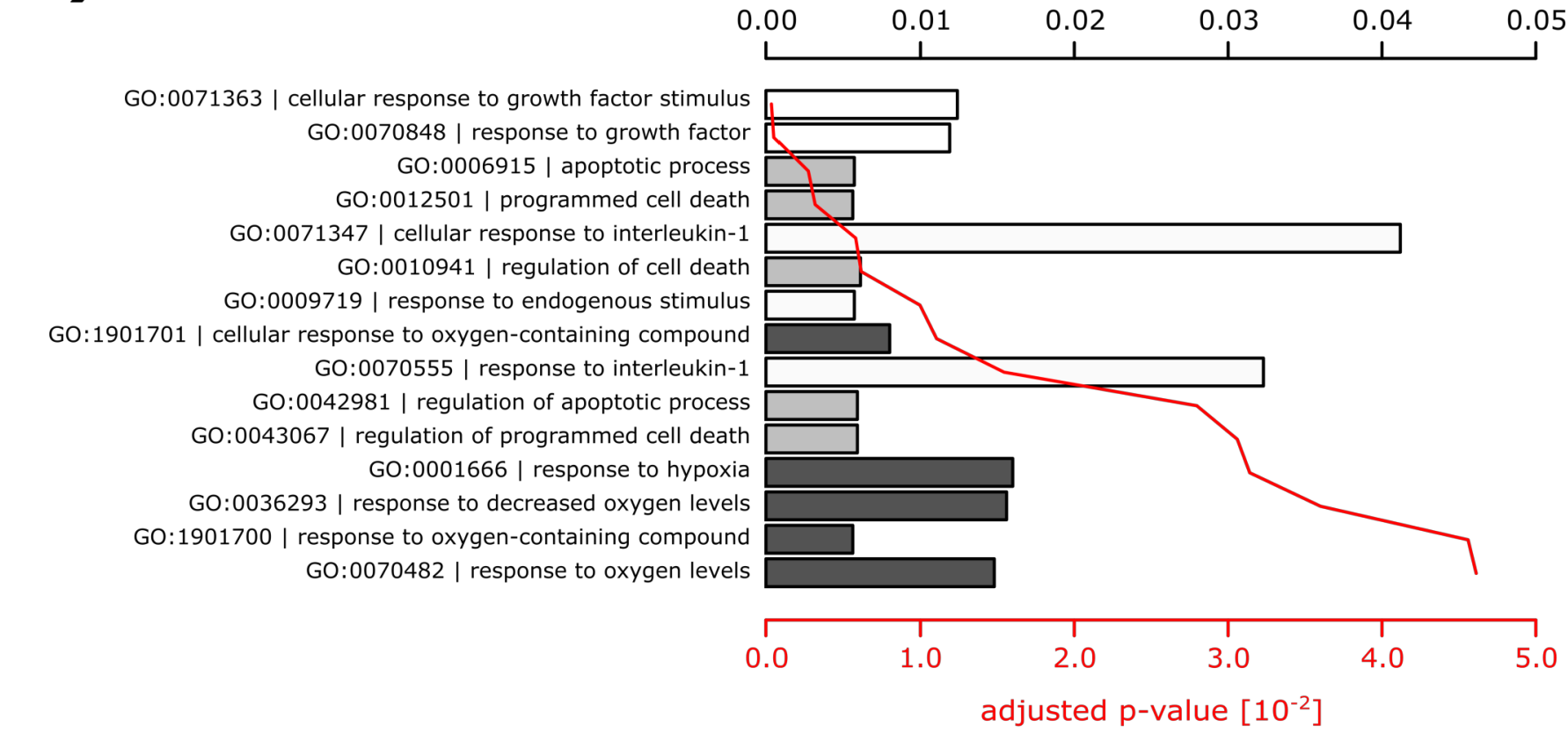

b)

identified vs. annotated genes

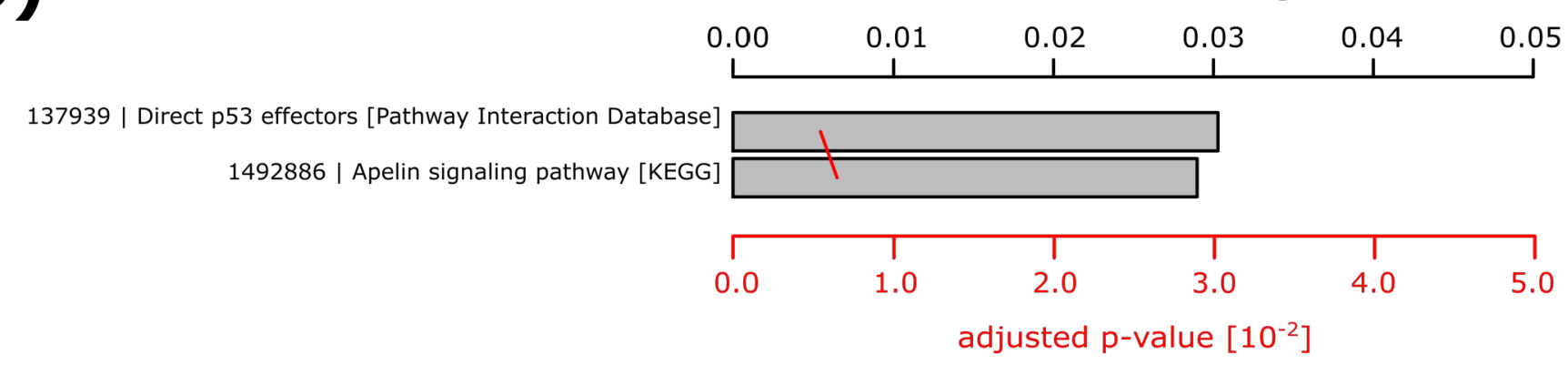

Figure S5. Gene ontology and pathway analysis. DEGs with at least 2-fold expression change were (a) classified according to biological processes or (b) analyzed for pathway enrichment using ToppGene. Bars represent the ratio of identified genes versus all annotated genes in the corresponding biological classification or pathway, respectively. Only top 15 biological processes are presented. Multiple testing correction was performed according to the method of Bonferroni and produced an adjusted $p$-value depicted as red curve. 
Table S1. Identified genes with at least 1.5-fold expression change upon treatment with origamicin

\begin{tabular}{|c|c|c|c|c|c|}
\hline Row ID & Gene Symbol & HGNC Gene Title & $\log _{2} F C$ & p-value & adj. p-value \\
\hline 16827679 & NQO1 & $\mathrm{NAD}(\mathrm{P}) \mathrm{H}$ dehydrogenase, quinone 1 & 3.0495 & 0.0000 & 0.0003 \\
\hline 16716478 & ANKRD1 & ankyrin repeat domain 1 (cardiac muscle) & 1.9529 & 0.0000 & 0.0208 \\
\hline 16979917 & SLC7A11 & $\begin{array}{l}\text { solute carrier family } 7 \text { (anionic amino acid transporter light chain, xc- system), } \\
\text { member } 11\end{array}$ & 1.8432 & 0.0004 & 0.0593 \\
\hline 16859795 & GDF15 & growth differentiation factor 15 & 1.7628 & 0.0000 & 0.0077 \\
\hline 17049676 & SERPINE1 & $\begin{array}{l}\text { serpin peptidase inhibitor, clade } E \text { (nexin, plasminogen activator inhibitor type } \\
\text { 1), member } 1\end{array}$ & 1.6776 & 0.0002 & 0.0427 \\
\hline 17059828 & TFPI2 & tissue factor pathway inhibitor 2 & 1.5298 & 0.0000 & 0.0124 \\
\hline 17044372 & NPY & neuropeptide $Y$ & 1.4995 & 0.0000 & 0.0243 \\
\hline 16970435 & SPRY1 & sprouty RTK signaling antagonist 1 & 1.3960 & 0.0003 & 0.0566 \\
\hline 16833204 & CCL2 & chemokine (C-C motif) ligand 2 & 1.3926 & 0.0034 & 0.1161 \\
\hline 16830910 & MIR4521 & microRNA 4521 & 1.2590 & 0.0009 & 0.0756 \\
\hline 16996433 & PLK2 & polo-like kinase 2 & 1.1990 & 0.0017 & 0.0910 \\
\hline 16724800 & LOC101927120 & uncharacterized LOC101927120 & 1.0994 & 0.0026 & 0.1036 \\
\hline 16738400 & APLNR & apelin receptor & 1.0992 & 0.0072 & 0.1500 \\
\hline 16989736 & EGR1 & early growth response 1 & 1.0732 & 0.0000 & 0.0208 \\
\hline 16728986 & MIR548AL & microRNA 548al & 1.0585 & 0.0079 & 0.1539 \\
\hline 16872452 & BLVRB & biliverdin reductase $B$ & 1.0404 & 0.0000 & 0.0287 \\
\hline 17120156 & LOC101060632 & putative ankyrin repeat domain-containing protein $20 \mathrm{~A} 12$ pseudogene & 1.0364 & 0.0053 & 0.1349 \\
\hline 17085951 & RORB & RAR-related orphan receptor B & 0.9927 & 0.0000 & 0.0177 \\
\hline 17048450 & GNG11 & guanine nucleotide binding protein ( $\mathrm{G}$ protein), gamma 11 & 0.9824 & 0.0000 & 0.0208 \\
\hline 16839220 & FAM101B & family with sequence similarity 101 , member $B$ & 0.9662 & 0.0000 & 0.0177 \\
\hline 17060824 & VGF & VGF nerve growth factor inducible & 0.9583 & 0.0003 & 0.0537 \\
\hline 16784207 & PTGER2 & prostaglandin E receptor 2 (subtype EP2), 53kDa & 0.9462 & 0.0002 & 0.0427 \\
\hline 17044253 & GPNMB & glycoprotein (transmembrane) nmb & 0.9347 & 0.0075 & 0.1512 \\
\hline 16658641 & LOC102724571 & uncharacterized LOC102724571 & 0.9307 & 0.0053 & 0.1357 \\
\hline 16761820 & MGP & matrix Gla protein & 0.9204 & 0.0090 & 0.1638 \\
\hline 16984945 & MAP3K1 & mitogen-activated protein kinase kinase kinase 1, E3 ubiquitin protein ligase & 0.9027 & 0.0000 & 0.0208 \\
\hline 16913572 & SNORA60 & small nucleolar RNA, H/ACA box 60 & 0.8797 & 0.0001 & 0.0309 \\
\hline
\end{tabular}




\begin{tabular}{|c|c|c|c|c|c|}
\hline 17023810 & SGK1 & serum/glucocorticoid regulated kinase 1 & 0.8768 & 0.0046 & 0.1284 \\
\hline 16799315 & THBS1 & thrombospondin 1 & 0.8656 & 0.0003 & 0.0561 \\
\hline 16700058 & ITPKB & inositol-trisphosphate 3-kinase B & 0.8575 & 0.0005 & 0.0645 \\
\hline 16944695 & PARP14 & poly (ADP-ribose) polymerase family, member 14 & 0.8574 & 0.0016 & 0.0882 \\
\hline 16710548 & PTPRE & protein tyrosine phosphatase, receptor type, E & 0.8539 & 0.0014 & 0.0854 \\
\hline 17111725 & EDA2R & ectodysplasin A2 receptor & 0.8277 & 0.0000 & 0.0186 \\
\hline 17075992 & LINC00589 & long intergenic non-protein coding RNA 589 & 0.8254 & 0.0013 & 0.0843 \\
\hline 16696685 & SCARNA3 & small Cajal body-specific RNA 3 & 0.8200 & 0.0008 & 0.0722 \\
\hline 16984304 & $\mathrm{C} 7$ & complement component 7 & 0.8146 & 0.0000 & 0.0237 \\
\hline 17001063 & SPRY4 & sprouty RTK signaling antagonist 4 & 0.8143 & 0.0001 & 0.0377 \\
\hline 17098594 & ENG & endoglin & 0.8092 & 0.0001 & 0.0404 \\
\hline 16691619 & LINC00622 & long intergenic non-protein coding RNA 622 & 0.8069 & 0.0055 & 0.1377 \\
\hline 16778355 & LHFP & lipoma HMGIC fusion partner & 0.8038 & 0.0000 & 0.0219 \\
\hline 17091554 & UAP1L1 & UDP-N-acetylglucosamine pyrophosphorylase 1 like 1 & 0.8026 & 0.0003 & 0.0521 \\
\hline 16830016 & KIF1C & kinesin family member $1 \mathrm{C}$ & 0.8016 & 0.0001 & 0.0287 \\
\hline 17062479 & TMEM229A & transmembrane protein 229A & 0.8009 & 0.0000 & 0.0208 \\
\hline 16766578 & DDIT3 & DNA-damage-inducible transcript 3 & 0.7993 & 0.0099 & 0.1701 \\
\hline 17025564 & LINC00473 & long intergenic non-protein coding RNA 473 & 0.7961 & 0.0010 & 0.0773 \\
\hline 17050797 & CPED1 & cadherin-like and PC-esterase domain containing 1 & 0.7960 & 0.0027 & 0.1046 \\
\hline 16683377 & ID3 & inhibitor of DNA binding 3, dominant negative helix-loop-helix protein & 0.7906 & 0.0005 & 0.0663 \\
\hline 16858451 & LPPR2 & lipid phosphate phosphatase-related protein type 2 & 0.7867 & 0.0001 & 0.0287 \\
\hline 16848318 & ABCA5 & ATP-binding cassette, sub-family A (ABC1), member 5 & 0.7824 & 0.0029 & 0.1076 \\
\hline 17023150 & MAN1A1 & mannosidase, alpha, class $1 \mathrm{~A}$, member 1 & 0.7820 & 0.0001 & 0.0308 \\
\hline 16982269 & FAT1 & FAT atypical cadherin 1 & 0.7801 & 0.0000 & 0.0287 \\
\hline 16912362 & ID1 & inhibitor of DNA binding 1 , dominant negative helix-loop-helix protein & 0.7786 & 0.0004 & 0.0592 \\
\hline 16731084 & SIK2 & salt-inducible kinase 2 & 0.7786 & 0.0000 & 0.0208 \\
\hline 16827041 & $\mathrm{CDH} 11$ & cadherin 11 , type $2, \mathrm{OB}$-cadherin (osteoblast) & 0.7614 & 0.0001 & 0.0294 \\
\hline 16694357 & SNORA80E & small nucleolar RNA, H/ACA box 80E & 0.7599 & 0.0022 & 0.0974 \\
\hline 16689752 & GCLM & glutamate-cysteine ligase, modifier subunit & 0.7597 & 0.0001 & 0.0299 \\
\hline
\end{tabular}




\begin{tabular}{|c|c|c|c|c|c|}
\hline 16859800 & MIR3189 & microRNA 3189 & 0.7507 & 0.0455 & 0.3068 \\
\hline 16844653 & KRT33B & keratin 33B, type I & 0.7476 & 0.0269 & 0.2499 \\
\hline 17002657 & MIR218-2 & microRNA 218-2 & 0.7465 & 0.0365 & 0.2834 \\
\hline 16978779 & DKK2 & dickkopf WNT signaling pathway inhibitor 2 & 0.7464 & 0.0010 & 0.0773 \\
\hline 17008007 & CDKN1A & cyclin-dependent kinase inhibitor $1 \mathrm{~A}(\mathrm{p} 21, \mathrm{Cip} 1)$ & 0.7302 & 0.0004 & 0.0574 \\
\hline 16998059 & ARRDC3 & arrestin domain containing 3 & 0.7278 & 0.0001 & 0.0404 \\
\hline 16707149 & FAS & Fas cell surface death receptor & 0.7251 & 0.0006 & 0.0683 \\
\hline 16755908 & DRAM1 & DNA-damage regulated autophagy modulator 1 & 0.7231 & 0.0325 & 0.2698 \\
\hline 17074721 & LOC441268 & uncharacterized LOC441268 & 0.7222 & 0.0264 & 0.2484 \\
\hline 16991582 & NIPAL4 & NIPA-like domain containing 4 & 0.7187 & 0.0101 & 0.1714 \\
\hline 16705011 & DKK1 & dickkopf WNT signaling pathway inhibitor 1 & 0.7184 & 0.0000 & 0.0208 \\
\hline 16966685 & SPATA18 & spermatogenesis associated 18 & 0.7119 & 0.0007 & 0.0699 \\
\hline 16756163 & TXNRD1 & thioredoxin reductase 1 & 0.7061 & 0.0000 & 0.0265 \\
\hline 16967077 & THEGL & theg spermatid protein-like & 0.6997 & 0.0134 & 0.1910 \\
\hline 17056740 & ELMO1 & engulfment and cell motility 1 & 0.6885 & 0.0002 & 0.0427 \\
\hline 16993458 & SQSTM1 & sequestosome 1 & 0.6863 & 0.0001 & 0.0315 \\
\hline 16731068 & LAYN & layilin & 0.6849 & 0.0005 & 0.0629 \\
\hline 16979163 & ARSJ & arylsulfatase family, member $\mathrm{J}$ & 0.6787 & 0.0030 & 0.1105 \\
\hline 16858519 & ZNF441 & zinc finger protein 441 & 0.6781 & 0.0015 & 0.0854 \\
\hline 16740630 & FOSL1 & FOS-like antigen 1 & 0.6773 & 0.0014 & 0.0848 \\
\hline 16794278 & SLC8A3 & solute carrier family 8 (sodium/calcium exchanger), member 3 & 0.6758 & 0.0155 & 0.2028 \\
\hline 16922495 & CBR3 & carbonyl reductase 3 & 0.6742 & 0.0095 & 0.1659 \\
\hline 16856803 & GADD45B & growth arrest and DNA-damage-inducible, beta & 0.6708 & 0.0309 & 0.2638 \\
\hline 17057478 & IGFBP3 & insulin-like growth factor binding protein 3 & 0.6707 & 0.0006 & 0.0683 \\
\hline 16800229 & MAP1A & microtubule-associated protein $1 \mathrm{~A}$ & 0.6705 & 0.0002 & 0.0442 \\
\hline 16703036 & PLXDC2 & plexin domain containing 2 & 0.6686 & 0.0213 & 0.2282 \\
\hline 16988837 & SLC27A6 & solute carrier family 27 (fatty acid transporter), member 6 & 0.6597 & 0.0080 & 0.1539 \\
\hline 16691766 & ANKRD20A12P & ankyrin repeat domain 20 family, member $\mathrm{A} 12$, pseudogene & 0.6593 & 0.0279 & 0.2534 \\
\hline 17117823 & C19orf25 & chromosome 19 open reading frame 25 & 0.6588 & 0.0031 & 0.1132 \\
\hline
\end{tabular}




\begin{tabular}{|c|c|c|c|c|c|}
\hline 16951567 & THRB & thyroid hormone receptor, beta & 0.6578 & 0.0010 & 0.0783 \\
\hline 16957807 & POPDC2 & popeye domain containing 2 & 0.6560 & 0.0001 & 0.0332 \\
\hline 16810329 & RPS27L & ribosomal protein S27-like & 0.6556 & 0.0009 & 0.0756 \\
\hline 16666738 & CYR61 & cysteine-rich, angiogenic inducer, 61 & 0.6537 & 0.0021 & 0.0967 \\
\hline 16998551 & SLCO4C1 & solute carrier organic anion transporter family, member $4 \mathrm{C} 1$ & 0.6511 & 0.0002 & 0.0427 \\
\hline 16703056 & MIR4675 & microRNA 4675 & 0.6469 & 0.0079 & 0.1533 \\
\hline 16915213 & C20orf85 & chromosome 20 open reading frame 85 & 0.6456 & 0.0350 & 0.2774 \\
\hline 16768270 & KITLG & KIT ligand & 0.6436 & 0.0002 & 0.0427 \\
\hline 16826779 & DOK4 & docking protein 4 & 0.6368 & 0.0000 & 0.0208 \\
\hline 16961773 & ZMAT3 & zinc finger, matrin-type 3 & 0.6345 & 0.0000 & 0.0287 \\
\hline 17070110 & PI15 & peptidase inhibitor 15 & 0.6342 & 0.0001 & 0.0424 \\
\hline 16775856 & DNAJC3 & DnaJ (Hsp40) homolog, subfamily C, member 3 & 0.6268 & 0.0001 & 0.0387 \\
\hline 17021738 & $\mathrm{BACH} 2$ & BTB and CNC homology 1, basic leucine zipper transcription factor 2 & 0.6220 & 0.0005 & 0.0648 \\
\hline 16798951 & GREM1 & gremlin 1, DAN family BMP antagonist & 0.6214 & 0.0066 & 0.1457 \\
\hline 17075426 & TNFRSF10B & tumor necrosis factor receptor superfamily, member $10 \mathrm{~b}$ & 0.6168 & 0.0001 & 0.0404 \\
\hline 16982931 & UBE2QL1 & ubiquitin-conjugating enzyme E2Q family-like 1 & 0.6148 & 0.0001 & 0.0404 \\
\hline 16754134 & LGR5 & leucine-rich repeat containing G protein-coupled receptor 5 & 0.6131 & 0.0000 & 0.0287 \\
\hline 16909413 & SP110 & SP110 nuclear body protein & 0.6128 & 0.0184 & 0.2155 \\
\hline 16732676 & UBASH3B & ubiquitin associated and $\mathrm{SH} 3$ domain containing $\mathrm{B}$ & 0.6110 & 0.0064 & 0.1438 \\
\hline 16892446 & INPP5D & inositol polyphosphate-5-phosphatase D & 0.6105 & 0.0168 & 0.2079 \\
\hline 16672428 & ACKR1 & atypical chemokine receptor 1 (Duffy blood group) & 0.6103 & 0.0047 & 0.1289 \\
\hline 16855673 & BCL2 & B-cell CLL/lymphoma 2 & 0.6068 & 0.0000 & 0.0265 \\
\hline 17106179 & ACSL4 & acyl-CoA synthetase long-chain family member 4 & 0.6060 & 0.0283 & 0.2544 \\
\hline 16805161 & SLCO3A1 & solute carrier organic anion transporter family, member 3A1 & 0.6009 & 0.0009 & 0.0756 \\
\hline 16963567 & KIAA0226 & KIAA0226 & 0.6006 & 0.0009 & 0.0752 \\
\hline 17000644 & ECSCR & endothelial cell surface expressed chemotaxis and apoptosis regulator & 0.6005 & 0.0275 & 0.2509 \\
\hline 17100467 & ENTPD8 & ectonucleoside triphosphate diphosphohydrolase 8 & 0.5999 & 0.0393 & 0.2898 \\
\hline 16752703 & NAB2 & NGFI-A binding protein 2 (EGR1 binding protein 2) & 0.5987 & 0.0006 & 0.0681 \\
\hline 17062664 & PRRT4 & proline-rich transmembrane protein 4 & 0.5986 & 0.0003 & 0.0566 \\
\hline
\end{tabular}




\begin{tabular}{|c|c|c|c|c|c|}
\hline 16731654 & TAGLN & transgelin & 0.5899 & 0.0045 & 0.1274 \\
\hline 16725984 & SLC3A2 & solute carrier family 3 (amino acid transporter heavy chain), member 2 & 0.5852 & 0.0001 & 0.0424 \\
\hline 16889631 & SNORD11 & small nucleolar RNA, C/D box 11 & -0.5856 & 0.0055 & 0.1375 \\
\hline 16867271 & TMIGD2 & transmembrane and immunoglobulin domain containing 2 & -0.5872 & 0.0042 & 0.1266 \\
\hline 16683612 & LOC100506985 & uncharacterized LOC100506985 & -0.5893 & 0.0047 & 0.1285 \\
\hline 16863684 & SEPW1 & selenoprotein $\mathrm{W}, 1$ & -0.5903 & 0.0030 & 0.1096 \\
\hline 17067605 & SMIM18 & small integral membrane protein 18 & -0.5943 & 0.0342 & 0.2744 \\
\hline 16671723 & $\mathrm{HCN} 3$ & hyperpolarization activated cyclic nucleotide gated potassium channel 3 & -0.5945 & 0.0010 & 0.0772 \\
\hline 16709822 & GRK5 & G protein-coupled receptor kinase 5 & -0.5953 & 0.0007 & 0.0722 \\
\hline 17100420 & NRARP & $\mathrm{NOTCH}$-regulated ankyrin repeat protein & -0.5982 & 0.0149 & 0.1990 \\
\hline 16942743 & ROBO2 & roundabout guidance receptor 2 & -0.5990 & 0.0002 & 0.0473 \\
\hline 16999888 & GDF9 & growth differentiation factor 9 & -0.6005 & 0.0337 & 0.2730 \\
\hline 16843221 & C17orf75 & chromosome 17 open reading frame 75 & -0.6008 & 0.0002 & 0.0489 \\
\hline 16870978 & ZNF675 & zinc finger protein 675 & -0.6015 & 0.0259 & 0.2466 \\
\hline 17016528 & ТОВ2Р1 & transducer of ERBB2, 2 pseudogene 1 & -0.6022 & 0.0286 & 0.2556 \\
\hline 17057736 & DDC & dopa decarboxylase (aromatic L-amino acid decarboxylase) & -0.6027 & 0.0000 & 0.0287 \\
\hline 16724568 & MIR4487 & microRNA 4487 & -0.6073 & 0.0175 & 0.2113 \\
\hline 17075198 & SLC18A1 & solute carrier family 18 (vesicular monoamine transporter), member 1 & -0.6073 & 0.0004 & 0.0592 \\
\hline 16780859 & EFNB2 & ephrin-B2 & -0.6088 & 0.0004 & 0.0595 \\
\hline 16785789 & GALNT16 & polypeptide $\mathrm{N}$-acetylgalactosaminyltransferase 16 & -0.6095 & 0.0041 & 0.1251 \\
\hline 16946341 & PXYLP1 & 2-phosphoxylose phosphatase 1 & -0.6102 & 0.0001 & 0.0424 \\
\hline 17076586 & ZMAT4 & zinc finger, matrin-type 4 & -0.6108 & 0.0036 & 0.1171 \\
\hline 16920923 & $\mathrm{HRH} 3$ & histamine receptor $\mathrm{H} 3$ & -0.6124 & 0.0002 & 0.0473 \\
\hline 16858800 & DAND5 & DAN domain family member 5 , BMP antagonist & -0.6139 & 0.0010 & 0.0773 \\
\hline 16961379 & LRRC34 & leucine rich repeat containing 34 & -0.6176 & 0.0059 & 0.1399 \\
\hline 17110948 & DGKK & diacylglycerol kinase, kappa & -0.6215 & 0.0023 & 0.0980 \\
\hline 16689828 & ARHGAP29 & Rho GTPase activating protein 29 & -0.6247 & 0.0026 & 0.1039 \\
\hline 16850047 & NOTUM & notum pectinacetylesterase homolog (Drosophila) & -0.6254 & 0.0129 & 0.1881 \\
\hline 16899476 & SNAR-H & small ILF3/NF90-associated RNA H & -0.6270 & 0.0004 & 0.0608 \\
\hline
\end{tabular}




\begin{tabular}{|c|c|c|c|c|c|}
\hline 17117626 & PPP2R5C & protein phosphatase 2 , regulatory subunit B', gamma & -0.6376 & 0.0232 & 0.2363 \\
\hline 17066083 & PDGFRL & platelet-derived growth factor receptor-like & -0.6401 & 0.0029 & 0.1075 \\
\hline 16704475 & FAM35DP & family with sequence similarity 35 , member A pseudogene & -0.6565 & 0.0117 & 0.1814 \\
\hline 16888437 & ZNF804A & zinc finger protein $804 \mathrm{~A}$ & -0.6591 & 0.0008 & 0.0751 \\
\hline 17000428 & GFRA3 & GDNF family receptor alpha 3 & -0.6625 & 0.0002 & 0.0427 \\
\hline 16897946 & BCL11A & B-cell CLL/lymphoma 11A (zinc finger protein) & -0.6639 & 0.0001 & 0.0332 \\
\hline 16916971 & PROKR2 & prokineticin receptor 2 & -0.6653 & 0.0131 & 0.1887 \\
\hline 16874512 & SNAR-D & small ILF3/NF90-associated RNA D & -0.6656 & 0.0005 & 0.0663 \\
\hline 16956285 & PDZRN3 & PDZ domain containing ring finger 3 & -0.6707 & 0.0011 & 0.0805 \\
\hline 16874005 & DBP & D site of albumin promoter (albumin D-box) binding protein & -0.6820 & 0.0001 & 0.0404 \\
\hline 16885859 & LOC101928161 & uncharacterized LOC101928161 & -0.6884 & 0.0235 & 0.2371 \\
\hline 17098171 & SNORD90 & small nucleolar RNA, C/D box 90 & -0.6911 & 0.0448 & 0.3052 \\
\hline 16975480 & LINC00682 & long intergenic non-protein coding RNA 682 & -0.6937 & 0.0006 & 0.0679 \\
\hline 16886491 & TNFAIP6 & tumor necrosis factor, alpha-induced protein 6 & -0.6980 & 0.0002 & 0.0427 \\
\hline 16880057 & $\mathrm{CHAC2}$ & ChaC, cation transport regulator homolog 2 (E. coli) & -0.7095 & 0.0151 & 0.2005 \\
\hline 16688153 & ROR1-AS1 & ROR1 antisense RNA 1 & -0.7132 & 0.0062 & 0.1420 \\
\hline 16903140 & CXCR4 & chemokine (C-X-C motif) receptor 4 & -0.7146 & 0.0000 & 0.0208 \\
\hline 17042997 & LFNG & LFNG O-fucosylpeptide 3-beta-N-acetylglucosaminyltransferase & -0.7147 & 0.0014 & 0.0848 \\
\hline 16920531 & CBLN4 & cerebellin 4 precursor & -0.7253 & 0.0147 & 0.1981 \\
\hline 16911201 & $\mathrm{CHGB}$ & chromogranin B & -0.7285 & 0.0001 & 0.0424 \\
\hline 17012516 & L3MBTL3 & I(3)mbt-like 3 (Drosophila) & -0.7295 & 0.0010 & 0.0773 \\
\hline 17122690 & VN1R108P & vomeronasal 1 receptor 108 pseudogene & -0.7299 & 0.0009 & 0.0758 \\
\hline 16879721 & EPAS1 & endothelial PAS domain protein 1 & -0.7382 & 0.0001 & 0.0287 \\
\hline 16739796 & RCOR2 & REST corepressor 2 & -0.7384 & 0.0000 & 0.0208 \\
\hline 16906175 & FRZB & frizzled-related protein & -0.7401 & 0.0003 & 0.0564 \\
\hline 16686273 & RNU5D-1 & RNA, U5D small nuclear 1 & -0.7402 & 0.0030 & 0.1105 \\
\hline 16887917 & HOXD13 & homeobox D13 & -0.7512 & 0.0003 & 0.0566 \\
\hline 16880814 & MEIS1 & Meis homeobox 1 & -0.7521 & 0.0001 & 0.0362 \\
\hline 16885244 & CNTNAP5 & contactin associated protein-like 5 & -0.7558 & 0.0004 & 0.0592 \\
\hline
\end{tabular}




\begin{tabular}{|c|c|c|c|c|c|}
\hline 16686271 & RNU5F-1 & RNA, U5F small nuclear 1 & -0.7657 & 0.0162 & 0.2048 \\
\hline 16716507 & PPP1R3C & protein phosphatase 1 , regulatory subunit $3 \mathrm{C}$ & -0.7706 & 0.0172 & 0.2099 \\
\hline 16761938 & LMO3 & LIM domain only 3 (rhombotin-like 2) & -0.7784 & 0.0001 & 0.0424 \\
\hline 16787650 & CHGA & chromogranin A & -0.7890 & 0.0000 & 0.0210 \\
\hline 17126014 & MIR3135B & microRNA 3135b & -0.7954 & 0.0456 & 0.3069 \\
\hline 16724973 & C11orf31 & chromosome 11 open reading frame 31 & -0.8106 & 0.0001 & 0.0287 \\
\hline 17101856 & NHS & Nance-Horan syndrome (congenital cataracts and dental anomalies) & -0.8150 & 0.0013 & 0.0842 \\
\hline 16900124 & IGKC & immunoglobulin kappa constant & -0.8172 & 0.0152 & 0.2014 \\
\hline 17123768 & LOC101928509 & uncharacterized LOC101928509 & -0.8227 & 0.0060 & 0.1409 \\
\hline 17055216 & ICA1 & islet cell autoantigen $1,69 \mathrm{kDa}$ & -0.8388 & 0.0001 & 0.0424 \\
\hline 16966855 & KIT & v-kit Hardy-Zuckerman 4 feline sarcoma viral oncogene homolog & -0.8540 & 0.0001 & 0.0424 \\
\hline 16842659 & ALDOC & aldolase C, fructose-bisphosphate & -0.8603 & 0.0006 & 0.0680 \\
\hline 16780133 & SLITRK6 & SLIT and NTRK-like family, member 6 & -0.8680 & 0.0000 & 0.0208 \\
\hline 17118035 & CRMP1 & collapsin response mediator protein 1 & -0.8836 & 0.0010 & 0.0773 \\
\hline 17010005 & ADGRB3 & adhesion G protein-coupled receptor B3 & -0.8865 & 0.0033 & 0.1146 \\
\hline 16891629 & NYAP2 & neuronal tyrosine-phosphorylated phosphoinositide-3-kinase adaptor 2 & -0.8924 & 0.0007 & 0.0699 \\
\hline 16774053 & CCNA1 & cyclin A1 & -0.9195 & 0.0007 & 0.0699 \\
\hline 17044862 & AQP1 & aquaporin 1 (Colton blood group) & -0.9236 & 0.0007 & 0.0683 \\
\hline 16829570 & SERPINF1 & $\begin{array}{l}\text { serpin peptidase inhibitor, clade } F \text { (alpha-2 antiplasmin, pigment epithelium } \\
\text { derived factor), member } 1\end{array}$ & -0.9448 & 0.0000 & 0.0208 \\
\hline 16881838 & HK2 & hexokinase 2 & -0.9611 & 0.0000 & 0.0208 \\
\hline 17072669 & MYC & v-myc avian myelocytomatosis viral oncogene homolog & -0.9757 & 0.0000 & 0.0208 \\
\hline 16837348 & MAP2K6 & mitogen-activated protein kinase kinase 6 & -1.0073 & 0.0001 & 0.0424 \\
\hline 17059165 & HGF & hepatocyte growth factor (hepapoietin A; scatter factor) & -1.0085 & 0.0006 & 0.0667 \\
\hline 16713048 & LOC100505502 & putative UPF0607 protein FLJ37424 & -1.0582 & 0.0055 & 0.1377 \\
\hline 17020617 & LOC101928307 & uncharacterized LOC101928307 & -1.0747 & 0.0002 & 0.0427 \\
\hline 16783414 & INSM2 & insulinoma-associated 2 & -1.0845 & 0.0000 & 0.0219 \\
\hline 17119758 & MIR3621 & microRNA 3621 & -1.0979 & 0.0016 & 0.0882 \\
\hline 16917183 & JAG1 & jagged 1 & -1.1219 & 0.0003 & 0.0508 \\
\hline 16923630 & LOC100505727 & uncharacterized LOC100505727 & -1.1682 & 0.0000 & 0.0187 \\
\hline
\end{tabular}


16887736 PDK1

16923643 TSPEAR-AS2

16705961 DDIT4

16923634 TSPEAR-AS1

16979056 NEUROG2

16852463 RAB27B pyruvate dehydrogenase kinase, isozyme 1

TSPEAR antisense RNA 2

DNA-damage-inducible transcript 4

TSPEAR antisense RNA 1

neurogenin 2

RAB27B, member RAS oncogene family $\begin{array}{lll}-1.2247 & 0.0000 & 0.0077\end{array}$

$\begin{array}{lll}-1.2291 & 0.0000 & 0.0208\end{array}$

$\begin{array}{lll}-1.3040 & 0.0000 & 0.0177\end{array}$

$\begin{array}{lll}-1.3351 & 0.0000 & 0.0124\end{array}$

$\begin{array}{lll}-1.5076 & 0.0000 & 0.0124\end{array}$

$\begin{array}{lll}-2.2583 & 0.0002 & 0.0473\end{array}$ 
Table S2. Selected genes for qRT-PCR validation

\begin{tabular}{llcl}
\hline Gene Title & Gene Symbol & $\log _{2}$ FC array & $\log _{2}$ FC qRT-PCR \\
\hline NQO1 & NAD(P)H dehydrogenase, quinone 1 & 3.0495 & 3.2503 \\
GDF15 & growth differentiation factor 15 & 1.7628 & 2.5701 \\
TXNIP & Thioredoxin-interacting protein & -0.5626 & -0.5147 \\
INSM2 & insulinoma-associated 2 & -1.0845 & -0.7699 \\
MYC & V-myc avian myelocytomatosis viral oncogene homolog & -0.9757 & -1.1239 \\
RAB27B & RAB27B, member RAS oncogene family & -2.2583 & -3.0305 \\
\hline
\end{tabular}


Table S3. List of oligonucleotides used in this study

\begin{tabular}{|c|c|c|c|}
\hline Application & Gene & Direction & Sequence \\
\hline \multirow[t]{2}{*}{ Cloning } & PDI & forward & 5'-GCACGGGCCCGGCTGCCTAGACCCTGCCTGACGGCGC-3' \\
\hline & & reverse & 5'-GCGCCGTCAGGCAGGGTCTAGGCAGCCGGGCCCGTGC-3' \\
\hline \multirow[t]{12}{*}{ qRT-PCR } & TXNIP & forward & 5'-ACTCGTGTCAAAGCCGTTAGG-3' \\
\hline & & reverse & 5'-TCCCTGCATCCAAAGCACTT-3' \\
\hline & RAB27B & forward & 5'-TGGCAACAAGGCAGACCTACCA-3' \\
\hline & & reverse & 5'-СTCCACATTCTGTCCAGTTGCTG-3' \\
\hline & MYC & forward & 5'-TGCTGCCAAGAGGGTCAAGT-3' \\
\hline & & reverse & 5'-GTGTGTTCGCCTCTTGACATT-3' \\
\hline & INSM2 & forward & 5'-TCССТССТCTGАССTCCCGA-3' \\
\hline & & reverse & 5'-ATCAGGAGTGGGAGCGGGTC-3' \\
\hline & NQO1 & forward & 5'-CTGCCATCATGCCTGACTAA-3' \\
\hline & & reverse & 5'-TGCAGATGTACGGTGTGGAT-3' \\
\hline & GDF15 & forward & 5'-CTCCAGATTCCGAGAGTTGC-3' \\
\hline & & reverse & 5'-AGAGATACGCAGGTGCAGGT-3' \\
\hline
\end{tabular}

